This document is confidential and is proprietary to the American Chemical Society and its authors. Do not copy or disclose without written permission. If you have received this item in error, notify the sender and delete all copies.

\title{
Enzymatic hydrolysis in the green production of bacterial cellulose nanocrystals
}

\begin{tabular}{|r|l|}
\hline Journal: & ACS Sustainable Chemistry \& Engineering \\
\hline Manuscript ID & Sc-2018-006007.R2 \\
\hline Manuscript Type: & Article \\
\hline Date Submitted by the Author: & 23-Apr-2018 \\
\hline Complete List of Authors: & $\begin{array}{l}\text { Rovera, Cesare; University of Milan, Food, Environmental and Nutritional } \\
\text { Sciences (DeFENS) } \\
\text { Ghaani, Masoud ; University of Milan, DeFENS - Department of Food, } \\
\text { Environmental and Nutritional Sciences } \\
\text { Santo, Nadia; Università degli Studi di Milano, Biosciences } \\
\text { Trabattoni, Silvia; University of Milano-Bicocca, Materials Science } \\
\text { Olsson, Richard; School of Chemsitry and Chemical Engineering, Fibre and } \\
\text { Polymer Technology } \\
\text { Romano, Diego; University of Milan, Department of Food, Environmental } \\
\text { and Nutritional Sciences - DeFENS, } \\
\text { Farris, Stefano; University of Milan, DeFENS - Department of Food, } \\
\text { Environmental and Nutritional Sciences ; National Consortium of Materials } \\
\text { Science and Technology, Local Unit of Milan }\end{array}$ \\
\hline
\end{tabular}

\section{SCHOLARONE}

Manuscripts 


\section{Enzymatic hydrolysis in the green production of}

\section{bacterial cellulose nanocrystals}

Cesare Rovera, ${ }^{\dagger}$ Masoud Ghaani, ${ }^{\dagger}$ Nadia Santo, ${ }^{\dagger}$ Silvia Trabattoni,${ }^{\S}$ Richard T. Olsson, $"$ Diego

Romano, ${ }^{+, \perp}$ Stefano Farris ${ }^{\dagger, \perp *}$

${ }^{\dagger}$ DeFENS, Department of Food, Environmental and Nutritional Sciences, University of Milan, via Celoria 2 - I-20133 Milan, Italy

*Department of Biosciences, University of Milan, via Celoria 26 - I-20133 Milan, Italy

$\S$ Department of Materials Science, University of Milano Bicocca, via R. Cozzi 55 - I-20125 Milan, Italy

" Department of Fibre and Polymer Technology, School of Chemical Science and Engineering, KTH Royal Institute of Technology, Teknikringen 56 - SE-10044 Stockholm, Sweden

${ }^{\perp}$ INSTM, National Consortium of Materials Science and Technology, Local Unit University of Milan, via Celoria 2 - I-20133 Milan, Italy

*Corresponding author. E-mail: stefano.farris@unimi.it

KEYWORDS: atomic force microscopy, modeling, morphology, kinetic, transmission electron microscopy, turbidity, yield 


\begin{abstract}
In this study, we extensively describe experimental models, with correlating experimental conditions, which were used to investigate the enzymatic hydrolysis of bacterial cellulose (BC) to obtain nanocrystals. Cellulase from Trichoderma reese $i$ was used in five enzyme/BC ratios over a period of $74 \mathrm{~h}$. The turbidity data was modeled using both logistic regression and empirical regression to determine the fractal kinetics, resulting in unique kinetic patterns for the mixtures that were richest in $\mathrm{BC}$ and in enzymes. The evolution of the yield was inversely related to the turbidity, as confirmed through a semi-empirical approach that was adopted to model the experimental data. The yield values after $74 \mathrm{~h}$ of hydrolysis were higher for the substrate-rich mixtures $(\sim 20 \%)$ than for the enzyme-rich mixtures $(\sim 5 \%)$, as corroborated by cellobiose and glucose quantification. Transmission electron microscopy and atomic force microscopy analyses revealed a shift from a fibril network to a needlelike morphology (i.e., aggregated nanocrystals or individual nanocrystals $\sim 6 \mathrm{~nm}$ width and 200-800 $\mathrm{nm}$ in length) as the enzyme/BC ratios went from lower to higher. These results were explained in terms of the heterogeneous substrate model and the erosion model. This work initiated a promising, environmental-friendly method that could serve as an alternative to the commonly used chemical hydrolysis routes.
\end{abstract}




\section{INTRODUCTION}

The exciting structure and properties of bacterial nanocellulose (BNC), a green nanomaterial, have been widely reviewed. ${ }^{1}$ Although bacterial cellulose (BC) has the same chemical composition as plant-derived cellulose, differences in the biosynthesis process lead to distinct structural properties. The most relevant aspects rely on the purity of the cellulose, which is produced by some species of acetic acid bacteria (in particular, Komagataeibacter xylinum and Komagataeibacter sucrofermentans). ${ }^{2}$ Pure cellulose is free of other plant components such as hemicellulose and lignin. Deviation from purity may have tremendous technical and economic consequences in all industrial settings.

From a technical point of view, the purity of BC dramatically affects the hierarchical assembly pattern of $\beta$-1,4-glucan chains in the cellulose I allomorph (the form that living cells assemble); the triclinic phase $\left(\mathrm{I}_{\alpha}\right)$ is the most abundant ( $70 \%$ from static cultures) in BNC, while the monoclinic phase $\left(I_{\beta}\right)$ is found in most plant cellulose. ${ }^{3}$ The highly ordered alignment and stacking of glucan chain sheets into crystal units, also known as cellulose nanocrystals, is reflected in native BC's higher inherent crystallinity (84-89\%) than its plant-derived counterpart (40-60\%), ${ }^{4,5}$ as Sacui et al. confirmed recently using a combined CPMAS-NMR/WAXS spectroscopy approach. ${ }^{6}$ This turns out to be important when considering practical uses of BC (e.g., the development of nanocomposite materials), as the crystalline structure greatly affects cellulose's mechanical and interfacial properties. $^{7}$ The unique mechanical anisotropy of BNC is responsible for its outstanding elastic modulus, with single-fibril measurements made by atomic force microscopy (AFM; e.g., tip bending) and Raman spectroscopy as high as $\sim 78 \mathrm{GPa}$ and $114 \mathrm{GPa}$, respectively. ${ }^{8,9}$ These values further increase if the crystalline phase is voided of contributions from the amorphous regions. In particular, Reiling and Brickmann estimated the crystal modulus of polymorph $\mathrm{I}_{\alpha}$ as being between $128 \mathrm{GPa}$ and $161 \mathrm{GPa},{ }^{10}$ and Eichhorn and Davies estimated it as being between 136 and $155 \mathrm{GPa} .{ }^{11}$ Regardless of the specific absolute value, the modulus of BNC is comparable with that of high-performance 
synthetic fibers such as aramid $(130 \mathrm{GPa})$ and is above that of aluminum $(70 \mathrm{GPa})$ and glass fibers $(76 \mathrm{GPa}) .^{12}$

From an economic point of view, Donini et al. compared the productivity of cellulose from plants and microorganisms. ${ }^{13}$ They found that the production of cellulose from 1 ha of eucalyptus (80 t of cellulose/ha after 7 years of cultivation) could be achieved with bacteria to a hypothetical yield of $15 \mathrm{~g} / \mathrm{L}$ in $50 \mathrm{~h}$ of culture (average of $0.3 \mathrm{~g} / \mathrm{h}$ ) in a bioreactor of $500 \mathrm{~m}^{3}$ in approximately 22 days. Moreover, obtaining high-purity $\mathrm{BC}$ involves a simpler procedure than obtaining plant-derived cellulose. Indeed, to overcome lignocellulose's inherent recalcitrance (the resistance of cell walls to deconstruction), a harsh first step is necessary to remove the lignin and hemicellulose and thus facilitate the subsequent processing. ${ }^{14}$ The delignification or fractionation of lignocellulose (which is usually carried out using a sulfite, chlorite, diluted-acid, or alkaline solution) is a cumbersome process that is also somewhat detrimental to the environment. ${ }^{15}$ In spite of that, while it is possible to devise an economically feasible biotechnological process for BNC production, by enzymatic hydrolysis, the high selling costs associated to its production are nowadays the main hurdle that restrain BNC to high-value niche markets. ${ }^{16}$ The main reason for this is the low yield of the fermentation process. ${ }^{17}$ Depending on the operating parameters (such as type of process, growth medium, strain, $\mathrm{pH}$, and temperature) values ranging between $4.0 \mathrm{~g} / \mathrm{L}$ and $16.0 \mathrm{~g} / \mathrm{L}$ have been reported ${ }^{18}$ Concerning BCNCs, yields in the range $21-38 \%$ and of $\sim 14 \%$ have been reported for acid hydrolysis ${ }^{19}$ and hydrolysis mediated by ammonium persulfate ${ }^{20}$ respectively. No data has been found on the yield of BCNCs obtained by enzymatic hydrolysis.

Because of BC's superior chemical purity, crystallinity, and biocompatibility, as well as its ultrafine network architecture and easy handling, it performs better than other conventional natural or synthesized counterparts, ${ }^{21}$ making its use possible for diverse sectors. The first commercially available BNC product (nata de coco) appeared in the $1990 \mathrm{~s} ;{ }^{22}$ since then, BNC has been used for a variety of applications, including textiles, cosmetics, medical or biomedical products, and food products. ${ }^{23}$ Other proposed uses of BNC include reinforced polymeric materials or paper; thickening 
agents or food stabilizers; food packaging; biomaterials for use in manufacturing cosmetics, artificial skin, artificial blood vessels, or engineered tissues; diaphragms for loudspeakers; and materials for use in the preparation of optically transparent films, electric conductors, or magnetic materials. ${ }^{24}$ To exploit BNC's full potential, it is crucial to isolate the crystalline phase from the amorphous domains, especially when bacterial cellulose nanocrystals (BCNCs) are intended to be a viable alternative to inorganic or mineral-based reinforced nanobuilding blocks for the generation of polymer nanocomposites with superior performance (e.g., mechanical, gas-barrier, and thermal performance).

Acid hydrolysis is the most widely employed method for obtaining cellulose nanocrystals from parental, macro-sized cellulose fibers, ${ }^{25}$ as also demonstrated by very recent works, where either hydrochloric acid or sulfuric acid were used to produce cellulose nanocrystals. ${ }^{26-31}$ However, cellulose fibers treated with sulfuric and hydrochloric acids yield crystals with poor thermal and mechanical properties, which can dramatically affect the composite's final performance. ${ }^{32}$ In addition, the use of concentrated acid solutions poses a serious environmental risk in terms of both disposal and energy consumption; this is in contrast with the increasing demand for innovative green and sustainable chemistry technologies. Therefore, it is a priority to investigate alternative CNCproduction routes that have less environmental impact but that do not jeopardize the native cellulose's structural properties. Ultrasonication has been proposed to achieve this goal, but a few studies have highlighted that it is more convenient when used only to assist in a main chemical route's procedure. ${ }^{33-35}$ The best-known application of enzymatic hydrolysis of cellulosic biomass is for biological conversion into fuels and chemicals, for which it has shown the potential to achieve higher yields, higher selectivity, lower energy costs, and milder operating conditions than are found in chemical processes. ${ }^{36}$ More recently, the current global focus on refining lignocellulose biomass has been expanded to also include intermediate products such as nanocellulose. ${ }^{37}$ Enzymatic hydrolysis could theoretically be employed as an approach with low environmental impact in the top-down reduction of cellulose to nanocrystals. In recent years, to make this process economically viable, much effort has been expended to increase cellulolytic enzymes' efficiency (e.g., by enhancing resistance 
to operational conditions such as $\mathrm{pH}$ and temperature, or by increasing speed) and reduce their price. As a result, a number of commercial mixtures using cellulase enzymes are available under various trade names (e.g., Celluclast ${ }^{\mathrm{TM}}$, Accelerase ${ }^{\mathrm{TM}}$, Spezyme $\mathrm{CP}^{\mathrm{TM}}$, and Viscoferm ${ }^{\mathrm{TM}}$ ). In fact, these mixtures include a variety of enzymes that are collectively known as cellulases: i) endo-1,4- $\beta$ glucanases (EGs), which target cellulose chains in random locations away from the chain ends; ii) exoglucanases or cellobiohydrolases (CBHs), which degrade cellulose by splitting off molecules from both ends of the chain, thus producing cellobiose dimers; and iii) $\beta$-glucosidases, which hydrolyze the cellobiose units that are produced during the EG and $\mathrm{CBH}$ attacks, turning them into glucose. ${ }^{38}$ EGs, in particular, quickly degrade the amorphous regions of the cellulose chains to produce smaller cellulose fragments, ${ }^{39}$ whereas CBHs typically attack the short crystalline regions of the cellulose. ${ }^{40}$ For this reason, cellulases can be used to obtain nanocrystals in nearly the same way as is used in acid hydrolysis.

A few works in the literature already reported on the enzymatic hydrolysis of BNC. SantaMaria and Jeoh used a cellobiohydrolase (Cel7A from Trichoderma reesei) to investigate changes in cellulose microstructure throughout the hydrolysis process by simultaneous confocal and atomic force microscopy. ${ }^{41}$ George et al. compared BCNC's morphological and thermal properties with those of acid-processed nanocrystals, which are components in polyvinylalcohol nanocomposites. ${ }^{32} \mathrm{Hu}$ et al. developed a bio-absorbable bacterial cellulose (BBC) material for wound dressing applications. The biodegradation of this material was investigated by in-vitro biodegradability tests using different enzymes (alone or in combination) as a function of $\mathrm{pH}$ values relevant to wound environments. ${ }^{42}$ In a similar study, Wang et al. evaluated the in vitro biodegradability of bacterial cellulose by cellulose in simulated body fluid. ${ }^{43}$ Domingues et al. compared CNCs obtained by acid hydrolysis of eucalyptus fibers with CNCs obtained upon enzymatic hydrolysis of bacterial cellulose. The main focus of this investigation was on the impact of the characteristic shape and surface chemistry of the two types of CNCs at oil/water interfaces and solid surfaces (cationized silica an polystyrene films). ${ }^{44}$ 
In this work, we investigate the possibility of producing BCNCs using commercially available enzymes preparation under controlled conditions ( $\mathrm{pH}$, temperature, and time). We systematically discuss for the first time the effect that the enzyme/cellulose ratio has on the BCNCs' final morphological properties and also consider the yield of the water suspensions thereof. In addition, we use a modeling approach to gather information on the kinetic of the hydrolysis reaction. The information stemming from this study can be used to further clarify enzymatic hydrolysis's potential as an alternative to chemical strategies for obtaining BCNCs.

\section{EXPERIMENTAL SECTION}

\section{Production of the macro-sized BC}

BC was produced by static fermentation using Komagataeibacter sucrofermentans DSM 15973 (Leibniz Institute DSMZ-German Collection of Microorganisms and Cell Cultures, Braunschweig Germany) in rectangular $\left(630 \times 430 \times 115 \mathrm{~mm}^{3}\right)$ polypropylene trays: $4 \mathrm{~L}$ of Hestrin and Schramm (HS) medium (glucose: $20 \mathrm{~g} / \mathrm{L}$; peptone: $5 \mathrm{~g} / \mathrm{L}$; yeast extract: $5 \mathrm{~g} / \mathrm{L} ; \mathrm{Na}_{2} \mathrm{HPO}_{4}: 2.7 \mathrm{~g} / \mathrm{L}$; citric acid: $1.15 \mathrm{~g} / \mathrm{L} ; \mathrm{pH}$ 6.0) were inoculated with $0.5 \mathrm{~L}$ of pre-culture (HS medium, 2L Erlenmeyer flask, growth for $48 \mathrm{~h}$ at $\left.30^{\circ} \mathrm{C}, 150 \mathrm{rpm}\right)$. After 7 days at $30^{\circ} \mathrm{C}$ the resulting $\mathrm{BC}$ pellicles were removed from the cultural medium, washed with deionized water and boiled in a $\mathrm{NaOH} 1 \mathrm{M}$ solution for 30 min to remove the residual bacterial cells. After cycles of washing with distilled water, the cellulosic material was homogenized for 15 min with an Ultra-turrax ${ }^{\circledR}$ T25 Basic homogenizer (Ika-Werke, Stanfen, Germany) at $12,000 \mathrm{rpm}$ and finally freeze-dried at $-55^{\circ} \mathrm{C}$ and 0.63 mbar for $24 \mathrm{~h}$ using an ALPHA 1-2 LDplus freeze dryer (Martin Christ, Osterode am Harz, Germany).

\section{Enzymatic hydrolysis}

A stock dispersion of $\mathrm{BC}$ was prepared by adding $12 \mathrm{~g}$ of freeze-dried $\mathrm{BC}$ to $88 \mathrm{~g}$ of distilled water. Then, $2 \mathrm{~g}$ of the stock dispersion was added to $40 \mathrm{~g}$ of sodium acetate buffer solution $(0.1 \mathrm{M}, \mathrm{pH}$ 5). The dispersion was homogenized using an Ultra-turrax ${ }^{\circledR}$ T25 Basic homogenizer (Ika-Werke, 
Stanfen, Germany) at $8,000 \mathrm{rpm}$ for $5 \mathrm{~min}$ and then kept in an incubator at $55 \pm 1^{\circ} \mathrm{C}$ overnight to facilitate the solvent's diffusion into the cellulose material and thus promote an even degradation of the amorphous parts upon adding the enzymatic mixture. The enzymatic hydrolysis was performed using cellulase from Trichoderma reesei (ATCC26921) in the form of lyophilized powder stock (Sigma Aldrich, Milano, enzymatic activity $\sim 6.5 \mathrm{U} / \mathrm{mg}$ solid). A stock solution of the enzyme in water ( $5 \mathrm{mg} / \mathrm{mL}$ ) was prepared to obtain various enzyme/BC mixtures (listed in Table 1). The enzymatic hydrolysis was conducted for a minimum of $2 \mathrm{~h}$ and a maximum of $74 \mathrm{~h}$, all at $55 \pm 1{ }^{\circ} \mathrm{C}$.

Table 1. Cellulase/BC mixtures with the related amount $(\mathrm{g})$ of cellulase water solution and enzymatic units (U).

\begin{tabular}{ccc}
\hline Cellulase $^{\mathrm{a}} / \mathrm{BC}^{\mathrm{b}}$ & Cellulase $^{\mathrm{a}}(\mathrm{g})$ & Enzyme Unit $(\mathrm{U})$ \\
\hline $1: 4$ & 0.5 & 16.25 \\
$1: 3$ & 0.66 & 21.45 \\
$1: 2$ & 1 & 32.50 \\
$1: 1$ & 2 & 65 \\
$2: 1$ & 4 & 130 \\
\hline
\end{tabular}

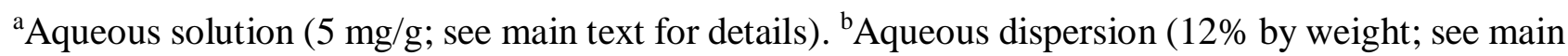
text for details).

\section{Analyses}

The evolution of the enzymatic hydrolysis was monitored at $2 \mathrm{~h}$ or $3 \mathrm{~h}$ intervals in turbidity experiments over a temporal window of $74 \mathrm{~h}$. Spectrophotometric measurements were performed using a Lambda 25 spectrophotometer (Perkin Elmer, Waltham, MA, USA) at wavelengths between $380 \mathrm{~nm}$ and $800 \mathrm{~nm}$ in transmittance mode. For each sample, the area under the transmittance spectrum was calculated by means of PerkinElmerUV WinLab software (version 6.0.4.0738) and plotted over time. 
The yield of the enzymatic process was gravimetrically determined every $2 \mathrm{~h}$ over a $74 \mathrm{~h}$ temporal window for each enzyme/BC combination collecting all the cellulosic material (Table 1). More specifically, $40 \mathrm{~mL}$ of the enzyme/BC water dispersion was centrifuged at 4,000 rpm $(2,630$ rcf or g-force) for 15 min using a Rotofix 32 A centrifuge (Hettich GmbH \& Co. KG, Tuttlingen, Germany). The resulting pellet, made of the hydrolyzed BC, was used for gravimetric analysis with a HS43S-MC halogen-lamp moisture-content analyzer (Mettler Toledo, Greifensee, Switzerland) set to $105^{\circ} \mathrm{C}$.

Cellobiose and glucose were the ultimate products of the enzymatic process and were quantified using high-performance liquid chromatography (HPLC). The supernatant that arose from the centrifugation of the enzyme/BC mixture (which was itself obtained after $74 \mathrm{~h}$ of hydrolysis) underwent a first centrifugation at 4,000 rpm (2,630 rcf or g-force) for $15 \mathrm{~min}$. The supernatant of this first centrifugation was in turn centrifuged at $14,000 \mathrm{rpm}(9,205 \mathrm{rcf}$ or g-force) for $5 \mathrm{~min}$ to completely remove the residual particles that were still present in the solution. The HPLC analysis was performed using a Merck Hitachi L-7100 system with an Aminex HPX-87P column (300 mm × $7.8 \mathrm{~mm}$; Biorad Laboratories, Hercules, CA, USA) and an evaporative light-scattering detector (Sedex 75; Sedere, Alfortville, France; conditions: He 3.5 bar, $50^{\circ} \mathrm{C}$ ). The analysis was carried out at $60^{\circ} \mathrm{C}$ using water $(0.5 \mathrm{~mL} / \mathrm{min})$ as the eluent.

Transmission electron microscope (TEM) was used to capture images of the BCNCs (a LEO $912 \mathrm{AB}$ energy-filtering transmission electron microscope operating at $80 \mathrm{kV}$; Zeiss, Oberkochen, Germany). Digital images were recorded with a ProScan 1K Slow-Scan CCD camera (ProScan, Scheuring, Germany). Samples for the TEM analyses were prepared according to the negative staining technique by drop-casting a few microliters of dispersion onto a glow-discharged Formvarcoated $\mathrm{Cu}$ grid (400-mesh) and letting the samples rest for 1-2 min, then blotting the excess of suspension and contrasting with uranyl acetate.

AFM experiments were performed using a Nanoscope V Multimode (Bruker, Karlsruhe, Germany) in intermittent-contact mode after dropping $10 \mu \mathrm{L}$ of 1:10 diluted BCNC dispersion onto 
a mica substrate. The images were collected at a resolution of $512 \times 512$ pixels using silicon tips (force constant: $3 \mathrm{~N} / \mathrm{m}$; resonance frequency: $\sim 75 \mathrm{kHz}$ ). Dimensional calculations for the acquired images were conducted with Nanoscope software (version 7.30; Bruker, Karlsruhe, Germany). The mean values reported for the BCNCs' dimensions were calculated from several images.

Information on the size distribution of BCNCs was obtained through photon correlation spectroscopy using a dynamic light-scattering (DLS) Zetasizer ZS90 instrument (Malvern Instruments Ltd., Malvern, UK). Analyses were carried out at $25^{\circ} \mathrm{C}$, with a stabilization time of $60 \mathrm{~s}$, and using water's viscosity $(\mathrm{v}=0.8872 \mathrm{cP})$ and refractive index $(\mathrm{n}=1.330)$ values. The software used the nonnegative least squares algorithm to calculate the size distribution.

The statistical significance of the mean values was determined via a one-way analysis of variance using StatgraphicsPlus 4.0 software (STSC, Rockville, MD, USA). The mean values, where appropriate, were separated using a least significant difference multiple-range test at $\mathrm{p}<0.05$. Modeling of the experimental data for the turbidity and yield experiments was performed by means of nonlinear regression, supported by the Levenberg-Marquardt algorithm, in Origin 8 software (OriginLab Corporation, Northampton, MA, USA). The comparison between the experimental transmittance data and those predicted by the models was performed using the root mean square error (RMSE), calculated as follows:

$$
R M S E=\sqrt{\frac{\sum_{i=1}^{n}\left(x_{\exp , i}-x_{p r e d, i}\right)^{2}}{n}}
$$

where $x_{\text {exp }, i}$ is the observed (measured) value, $x_{\text {pred }, i}$ is the value predicted by the model, and $n$ the number of the experimental measurements. RMSE is a widely used parameter to estimate the quality of model fitting as well as to compare the individual model performance. If $R M S E$ tends toward 0 or is very close to the experimental error, it means that model is able to represent the experimental data. 


\section{RESULTS AND DISCUSSION}

\section{Turbidity and hydrolysis kinetic analyses}

Turbidity experiments were carried out to monitor the evolution of the enzymatic hydrolysis. More specifically, decreased turbidity (i.e., increased transmittance) was expected for extended hydrolysis times as a consequence of reduced size of the BC fibrils. A decrease in size to the nanoscale level would reduce effect of the scattering phenomenon (and thus the turbidity of the BC water solution), as the wavelength of the incident light would be greater than or equal to the size of the newly formed BCNCs. As depicted in Figure 1, over time, the transmittance increased for all the enzyme/BC ratios until an apparent steady state was reached; this is a clear evidence of a decreased rate during the process, which is a typical feature of cellulose hydrolysis. ${ }^{37}$ Inhibition by cellobiose and glucose, enzyme deactivation, decreased substrate reactivity, decreased substrate accessibility, and decreased synergism between cellulases (among other factors) were reported as being the most relevant raterelenting factors. ${ }^{45}$ However, some obvious differences among the samples were detected in evolution of the transmittance and two different patterns were detected among the five transmittance-versustime curves depending on the enzyme concentration. While the plots of the 1:4, 1:3, and 1:2 mixtures showed an initial lag phase followed by a rising phase (Figure 1a), the curves obtained from the 1:1 and 2:1 mixtures exhibited an immediate climbing trend (Figure 1b). It is noteworthy that the BCcontaining water dispersions' initial transmittance value (i.e., after $2 \mathrm{~h}$ ) was proportionally higher for the mixtures that had lower amounts of enzymes; this demonstrates that, even after only $2 \mathrm{~h}$, the enzymatic hydrolysis produced an appreciable outcome for the mixtures richest in enzymes $(1: 1$ and 2:1). In addition, the maximum transmittance for the $1: 1$ and 2:1 mixtures was achieved after $\sim 30$ and $45 \mathrm{~h}$, respectively, after which a decrease was observed; the decrease was more marked for the $2: 1$ mixture. This decrease in transmittance (i.e., increase in turbidity) was probably due to the newly formed nanocrystals beginning to reaggregate after the completion of the hydrolysis reaction due to the extensive hydrogen bonding between the chemically unmodified (i.e., $-\mathrm{OH}$ rich) cellulose molecules. 

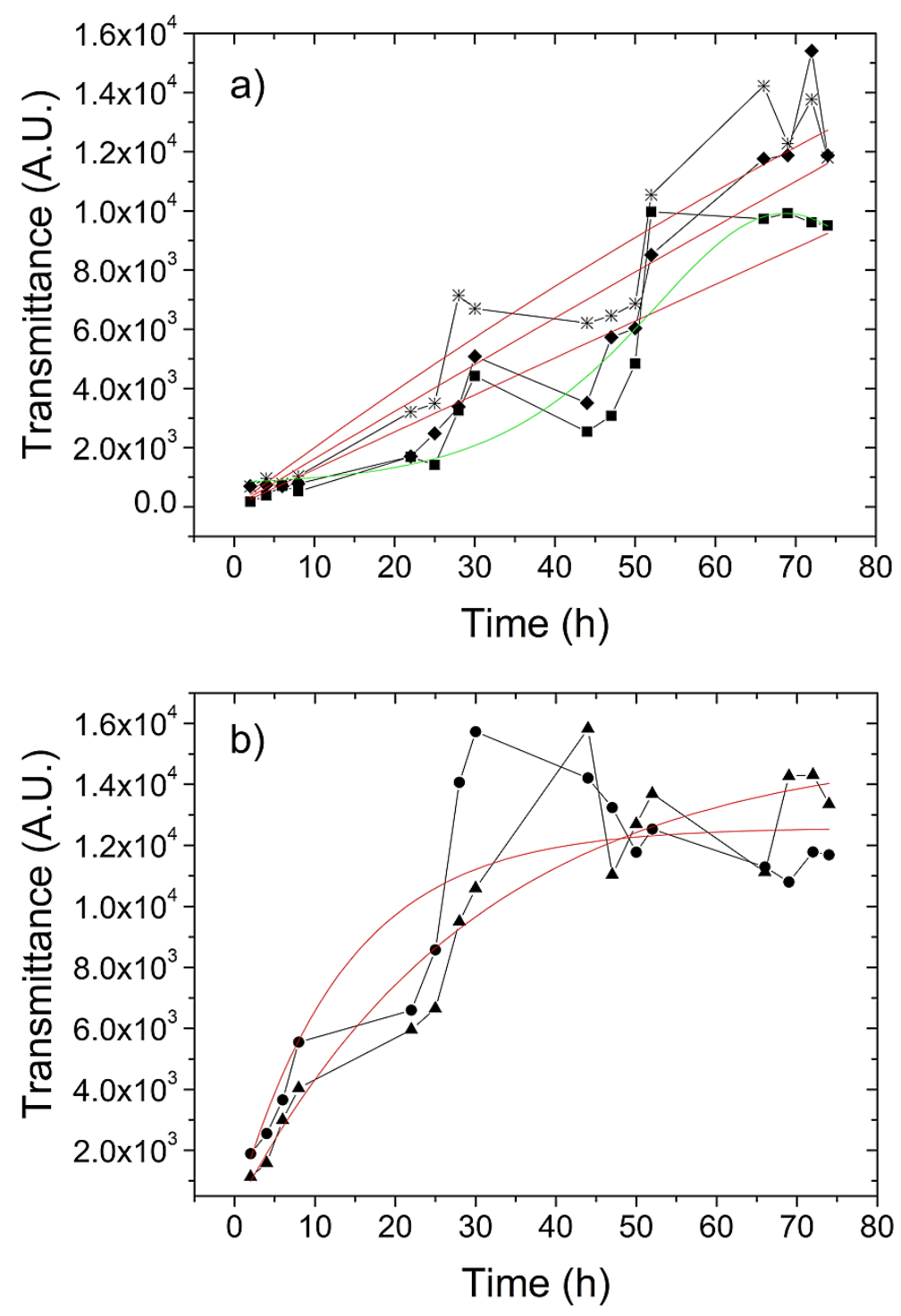

Figure 1. Evolution of transmittance (expressed as the area under each spectrum) during $74 \mathrm{~h}$ of hydrolysis for the enzyme/BC ratios of: (a) $1: 4(-\boldsymbol{-}-), 1: 3\left(-\boldsymbol{-}_{-}\right)$, and $1: 2\left(-\boldsymbol{*}_{-}\right)$; (b) $1: 1\left(-\boldsymbol{\Lambda}_{-}\right)$and 2:1 (--). The black lines connecting the experimental points are only to ensure clarity. The red and green lines are the fitting curves obtained from a nonlinear regression of the experimental data according to eq. 2 and eq. 3 (see the main text for details).

The two hydrolysis kinetics patterns described previously can be more clearly demonstrated by modeling the experimental transmittance data using the empirical model that Väljamäe et al. proposed for fractal kinetics, which are spatially heterogeneous reactions that are diffusion-limited, dimensionally restricted, or occurring on fractal surfaces: ${ }^{46}$ 


$$
p(t)=[S]_{0} \cdot\left[1-\exp \left(-k \cdot t^{(1-h)}\right)\right]
$$

where $p(t)$ is the concentration of released cellobiose (in $\mu \mathrm{M}$ ); $[S]_{0}$ is the initial concentration of the cellulose substrate, as represented as cellobiose units $(\mu \mathrm{M}) ; t$ is time; and $k$ and $h$ are empirical constants. To apply eq. 2 to our turbidity data, the product concentration and transparency were assumed to follow the same evolution; that is, in the time course of insoluble cellulose's enzymatic degradation, as the concentration of cellobiose increases, the transparency increases (or the turbidity decreases) proportionally. It must be pointed out that eq. 2 was used only for fitting purposes - to provide clear evidence of the two patterns observed during the native $\mathrm{BC}$ hydrolysis reaction for the various cellulose/enzyme ratios. Therefore, no physical meaning was assigned to the constants $k$ and $h$. As shown in Figure 1, the nonlinear regression of the hydrolysis data (expressed as transparency evolution) using eq. 2 yielded two prediction patterns, which is consistent with the experimental points. These two patterns are represented by the red lines of both panel (a) and panel (b) of Figure 1. In particular, the prediction for the 2:1 and 1:1 enzyme/BC mixtures followed the typical trend for the enzymatic hydrolysis of $\mathrm{BC}$, with an initial increase and subsequent decrease in the reaction rate (Figure 1b). The prediction for the remaining mixtures $(1: 2,1: 3$, and 1:4) provided by the same fractal model is instead represented by a straight line that denotes a different hydrolysis kinetics pattern for the mixtures containing a lower amount of enzyme (Figure 1a). This is further corroborated by the fact that a better prediction for the data sets of the 1:2, 1:3, and 1:4 mixtures was obtained using a logistic regression model (see the green line for the 1:4 mixture in Figure 1a):

$$
y=a+4 b \cdot n /(1+n)^{2}
$$

where $n=\exp (-(x-c) / d) ; a, b, c$, and $d$ are empirical parameters. Detailed information on the modeling of the experimental data using both eq. 2 and eq. 3 is reported in Figures S1-S5 of Supporting Information, together with the relevant statistical parameters arising from the fitting procedure (Table S1).

This study's logistic model is a sigmoid function that has been used to interpolate S-shaped data distributions for studies on topics such as tumor growth, ${ }^{47}$ toxicity and cytotoxicity, ${ }^{48-50}$ 
biodegradability, ${ }^{51}$ catalysis, ${ }^{52}$ microbial growth, ${ }^{53}$ biotechnological processes,${ }^{54}$ and food-texture evolution. ${ }^{55}$ In this work, the logistic regression model suggests that, for high substrate/enzyme ratios, the course of BC's enzymatic hydrolysis stays in a silent phase for the first approximately 6-8 h, contrary to what was observed for the mixtures richest in enzymes (i.e., the 1:1 and 2:1 mixtures).

These observations have a mechanistic explanation. Enzymatic hydrolysis of cellulosic biomass is a heterogeneous reaction that occurs on the surface of a substrate that is large enough to accommodate a large number of enzyme molecules. ${ }^{45}$ After the first adsorption of cellulases onto the substrate (phase 1), ${ }^{56}$ the two following steps more directly affect the hydrolysis rate: the location of a bond that is susceptible to hydrolysis on the substrate surface (phase 2$)^{57}$ and the formation of an enzyme-substrate complex (phase 3). ${ }^{58}$ Therefore, as the enzyme/cellulose ratio increases (and the amount of enzyme adsorbed on the cellulose surface increases), the hydrolytic reaction speeds up (given that the cellulosic substrate has the same characteristics in terms of, e.g., composition and crystallinity). The initial lag phase observed for the 1:4, 1:3, and 1:2 mixtures can thus be plausibly explained by considering the extended time that is necessary for phase 2 and phase 3 to take place due to the lower initial enzyme concentrations for those phases. In addition, the interaction between endo-type and exo-type enzymes must be considered. The most established mechanism is a sequential synergistic action whereby EGs initiate the attack on the cellulose by forming new chain ends, which then serve as attack sites for the endwise-acting CBHs' processive hydrolysis. ${ }^{59}$ This means that, for the mixtures with the fewest enzymes, an extended time is expected to elapse before the hydrolysis of BC can actively occur because the EGs must generate the new chain ends before the CBHs can start to processively hydrolyze the cellulose chains.

\section{Yield of the hydrolysis process}

The yield of the parental freeze-dried BC's hydrolysis reaction over $74 \mathrm{~h}$ is displayed in Figure 2a for all five enzyme/BC mixtures used in this work. The evolution of the yield is inversely related to the results of the turbidity experiments (i.e., the transmittance evolution is an indirect indication of the 
hydrolysis rate), as shown in Figure 1. The yield for the substrate-rich mixtures (i.e., 1:4 and 1:3) apparently decreased only slightly during the first $\sim 20 \mathrm{~h}$, reflecting the lag phase that was also observed in the turbidity experiments. After this time, the yield decreased more rapidly, indicating a more intensive hydrolysis reaction. By contrast, for the enzyme-rich mixtures (i.e., 1:1 and 2:1), the yield decreased rapidly during the first $\sim 10 \mathrm{~h}$ before decreasing, suggesting that the hydrolysis reaction had approached completion. A similar, though less pronounced, hydrolysis reaction was apparent for the 1:2 mixture.

Quantitative information on the yield evolution was obtained through a semi-empirical approach. The experimental yields collected during the $74 \mathrm{~h}$ period of analysis were first modeled via nonlinear regression, with the goal of obtaining a simple but adequate analytical expression (and its first derivative). In particular, a first-order (eq. 4) decay function was used for the 1:2 mixture, a second-order (eq. 5) decay function was used for the 1:1 and 2:1 mixtures, and a simple power function (eq. 6) was used for the 1:3 and 1:4 mixtures:

$$
\begin{aligned}
& y=y_{0}+a_{1} \exp \left(-x / b_{1}\right) \\
& y=y_{0}+a_{1} \exp \left(-x / b_{1}\right)+a_{2} \exp \left(-x / b_{2}\right) \\
& y=\left(a+b x^{2}\right)^{2}
\end{aligned}
$$

As shown in Figure 2a (solid lines), the selected functions fit the experimental data satisfactorily, which further supports the various kinetics that underlie the yield evolution and, in turn, the hydrolysis reaction. From a quantitative point of view, the first derivatives of the above functions provided indications of the process's rate. The yield rate decreased steeply from the beginning for the 1:1 and 2:1 mixtures, suggesting that the hydrolysis reaction was fully active after $2 \mathrm{~h}$ of incubation. After $\sim 30 \mathrm{~h}$, the yield rate approached a quasi-steady state, again denoting the completion of the process. A similar trend pertained to the 1:2 mixture, though it is worth noting that the initial rate in this mixture was almost four times lower than those of the 1:1 and 2:1 mixtures. 

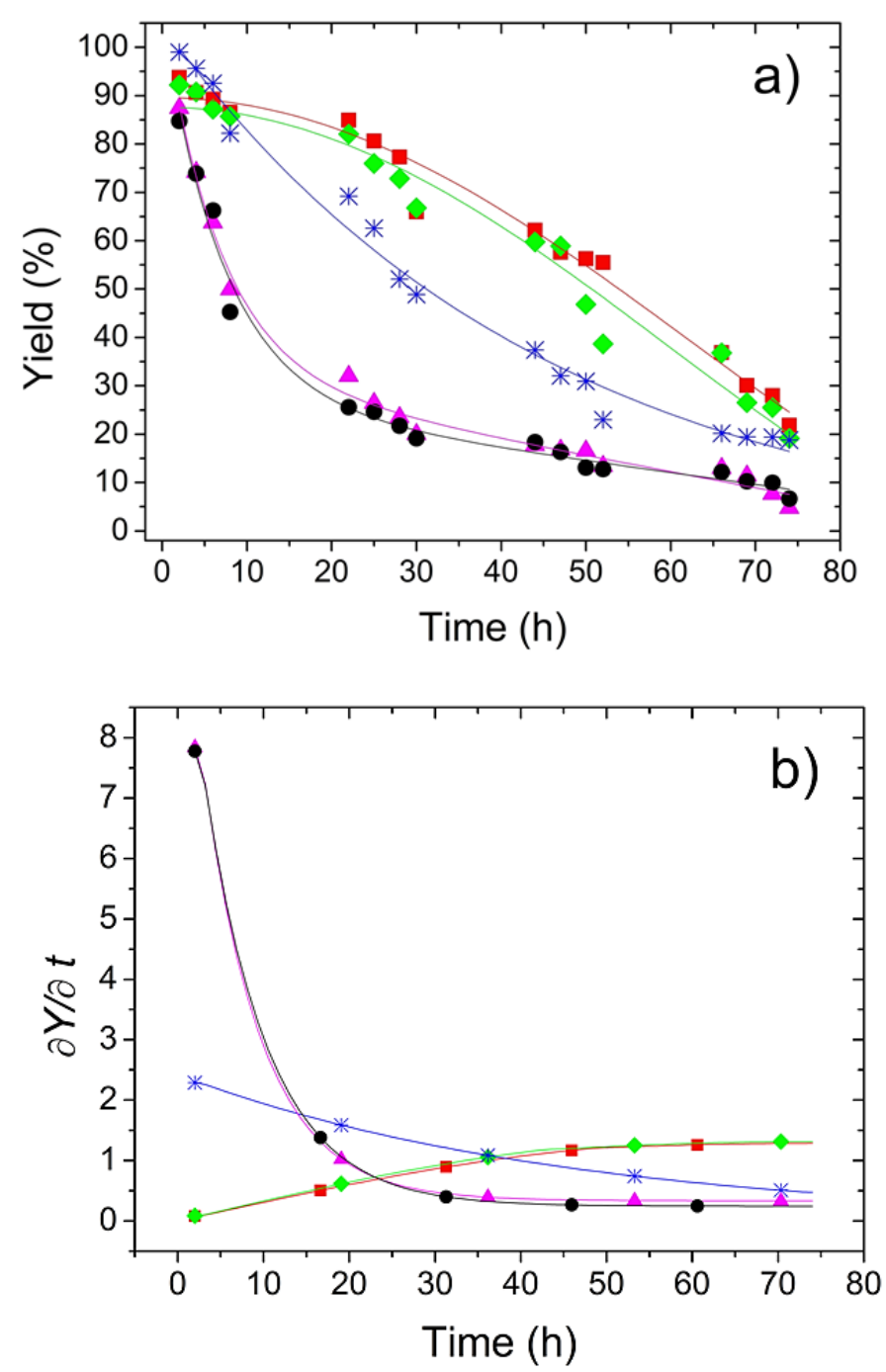

Figure 2. (a) Experimental (symbols) and predicted (solid lines) yield values of the various

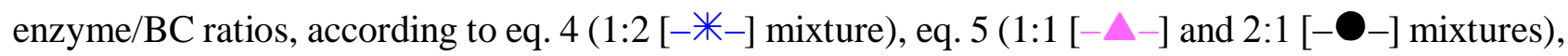
and eq. $6\left(1: 3\left[--_{-}\right]\right.$and 1:4 [- $[-]$mixtures). (b) First derivative of the fitting curves shown in panel (a). The symbols are only to aid in identification.

Interestingly, the first derivative of eq. 6 , which was used to interpolate the experimental yield data of the 1:3 and 1:4 mixtures, started at a zero-speed-rate state, further corroborating the presence of an initial latency phase in hydrolysis reactions involving substrate-rich mixtures. The rate slowly increased until reaching a steady state after $\sim 50 \mathrm{~h}$, and the resulting value was, in any case, much lower than the maximum rates recorded for the 1:1 and 2:1 mixtures (which were in the early stages of the hydrolysis process). These results demonstrate that the hydrolysis of BC at high substrate 
concentrations (the 1:3 and 1:4 mixtures) was not as efficient as for the enzyme-rich mixtures (the 1:1 and 2:1 mixtures). However, after $74 \mathrm{~h}$, the absolute yield was higher for the substrate-rich mixtures $(\sim 20 \%)$ than for the enzyme-rich mixtures $(\sim 5 \%)$. This has to be ascribed to the more intense hydrolysis process the occurred for the dispersions that contained the most enzymes (1:1 and 2:1).

The appearance of the water dispersions that contained hydrolyzed BC was markedly different from that of the initial mixture that contained the parental BC (Figure 3). After 74 h of hydrolysis, all the mixtures were slightly hazy and fully homogeneous (i.e., without any macroscopic cellulosic aggregate), especially the mixtures with the 1:1 and 2:1 enzyme/BC ratios. This strongly suggests that all samples decreased in size, though at different time scales (after approximately $50 \mathrm{~h}$ of hydrolysis for the 1:4, 1:3, and 1:2 mixtures and approximately $30 \mathrm{~h}$ for the $1: 1$ and 2:1 mixtures).

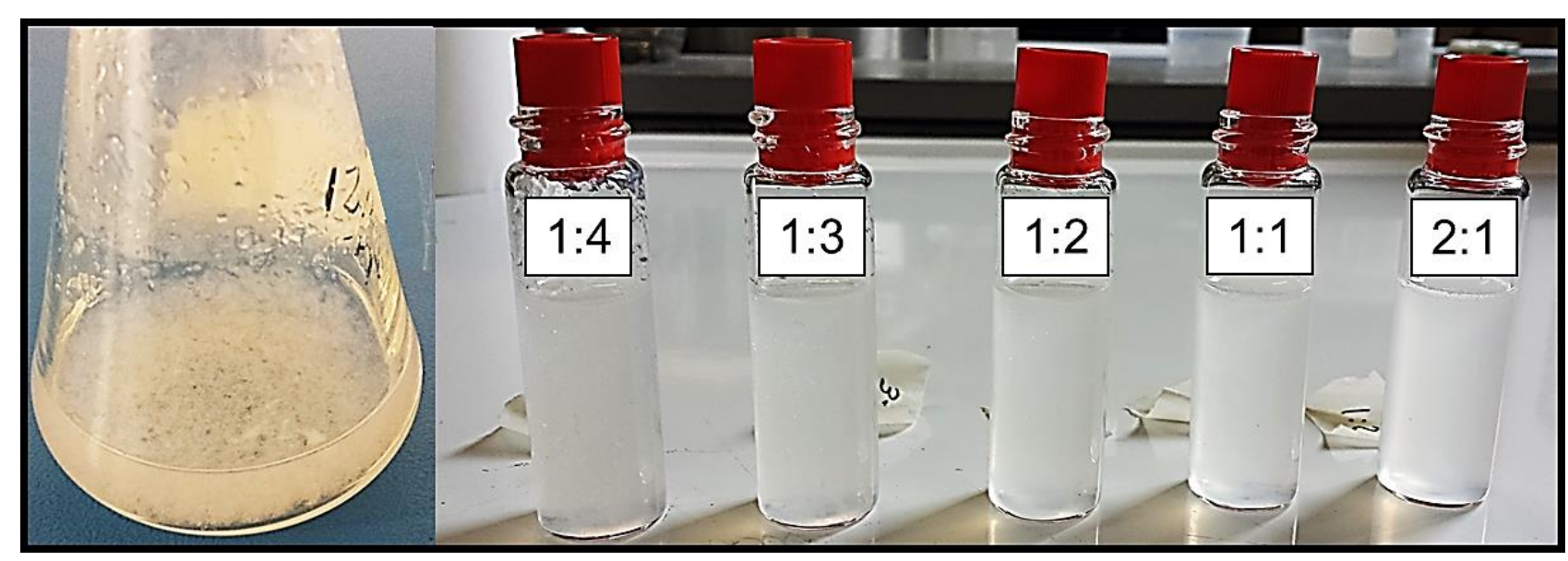

Figure 3. Photos of parental BC before hydrolysis (left) and of the enzyme/BC mixtures after $74 \mathrm{~h}$ of hydrolysis (right). Note the flakes in the parental dispersion and the decreasing hazy appearance moving from the 1:4 mixture to the 2:1 mixture.

\section{Cellobiose and glucose quantification}

The outcome of the HPLC analysis is reported in Figure 4. The concentrations of cellobiose and glucose were inversely related as a function of the enzyme/BC ratio; the disaccharide concentration decreased as the ratio decreased, whereas the hexose concentration increased monotonically as the 
amount of enzyme increased. These results confirm that more intense hydrolytic activity occurred at higher concentrations of enzyme. In addition, the conversion of cellobiose into glucose after $74 \mathrm{~h}$ (mostly by the $\beta$-glucosidases) was higher for the mixtures that were richer in enzymes, insomuch as no cellobiose was detected in the supernatant of the 2:1 mixture. Finally, the quantitative analysis of cellobiose and glucose was in agreement with the yields calculated for the five enzyme/BC mixtures: lower yields were associated with higher concentrations of glucose after $74 \mathrm{~h}$ of hydrolysis.

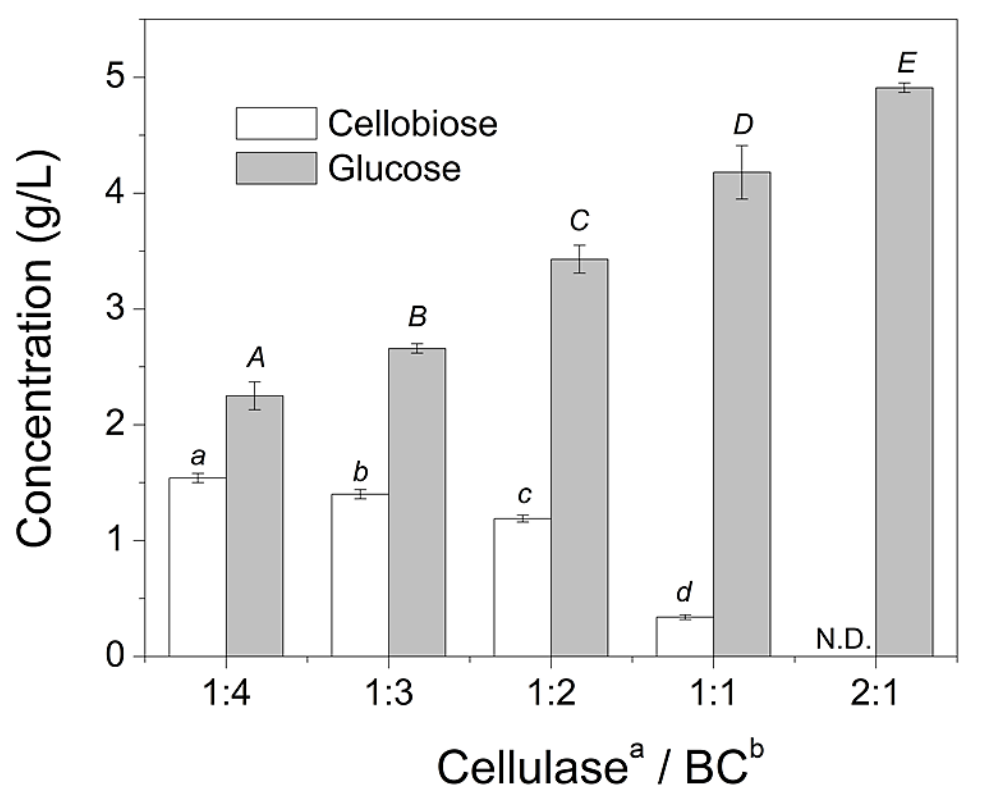

Figure 4. Cellobiose and glucose concentrations at the end of the $74 \mathrm{~h}$ BC hydrolysis reaction. Error bars represent the standard deviation around the mean value. The superscripts in italics refer to statistically significant differences within the same group $(p<0.05)$. ${ }^{a}$ Aqueous solution $(5 \mathrm{mg} / \mathrm{g}$; see main text for details). ${ }^{b}$ Aqueous dispersion ( $12 \%$ by weight; see main text for details). N.D.: Not determined.

\section{Morphological characterization of hydrolyzed BC}

Cellulose has a unique structure, as it is organized in a hierarchical fashion, with plant-derived cellulose and $\mathrm{BC}$ having quite distinct features due to certain differences in their respective biosynthesis processes. ${ }^{60}$ At a basic level, adjacent molecules interact via van der Waals forces and 
intermolecular hydrogen bonding promoting the arrangement of cellulose chains in elementary fibrils.

Within these cellulose fibrils there are regions where the cellulose chains are organized in a highly ordered (crystalline) structure, and regions that are disordered (amorphous-like). ${ }^{61}$ Although the interplay and spatial organization of these two phases has yet to be clarified, according to the existing literature it is likely that the amorphous phase is randomly distributed along and across the contour of the fibril. The crystalline domains are made of crystal units (known as cellulose nanocrystals) of 3-10 $\mathrm{nm}$ in width (depending on the source), i.e., highly ordered domains whereby cellulose chains adopt parallel configurations according to the specific hydrogen-bonding pattern of BC's allomorph $I_{\alpha .}{ }^{62}$ The next structural level involves the assembly of elementary fibrils to form cellulose nanofibrils (also called microfibrils) of $20-100 \mathrm{~nm}$ in width. ${ }^{63,64}$ Self-assembly of these nanofibrils leads to a third level of structural organization, which, for BC, involves flat ribbons with rectangular crosssections. ${ }^{65,66}$
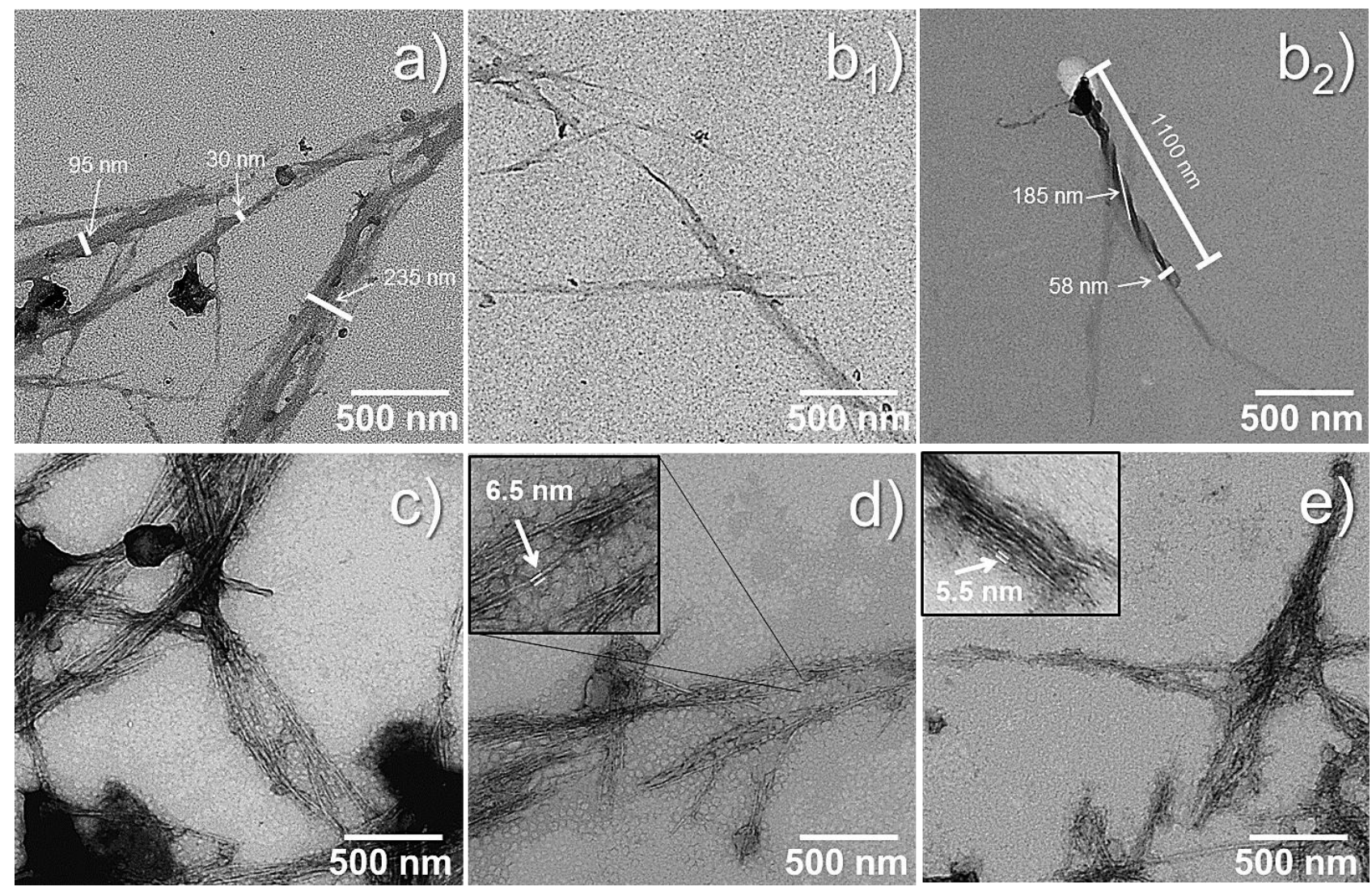

Figure 5. Transmission electron microscopy images of hydrolyzed bacterial cellulose after $74 \mathrm{~h}$ according to the following enzyme/BC ratios: (a) 1:4, ( $b_{1}$ and $b_{2}$ ) 1:3, (c) 1:2, (d) 1:1, and (e) 2:1. 
The enzymatic hydrolysis yielded different morphologies depending on the enzyme/BC ratio, as seen in Figures 5 and 6, which show representative TEM and AFM images, respectively. A shift occurs from a network of fibrils at lower enzyme/BC ratios to a thinner morphology at higher ratios (e.g., see panels a through e of Figure 5). In particular, flat ribbons of variable width in the range of 50-100 nm were observed for the 1:4 and 1:3 mixtures (Figures $5 \mathrm{a}$ and $5 \mathrm{~b}_{1}$ ), with bundles of ribbons still present in the 1:4 mixture. A markedly different morphology was observed for the 1:2 enzyme/BC ratio, for which thin nanofibrils were tightly connected, forming a bundle rather than isolated particles (Figure 5c). This change in morphology was accompanied by a marked reduction in size (compare panels a1 and a2 with panels c1 and c2 in Figure 6), whereby thinner particles (although of similar length) were obtained from the 1:2 mixture (Figure 6c).

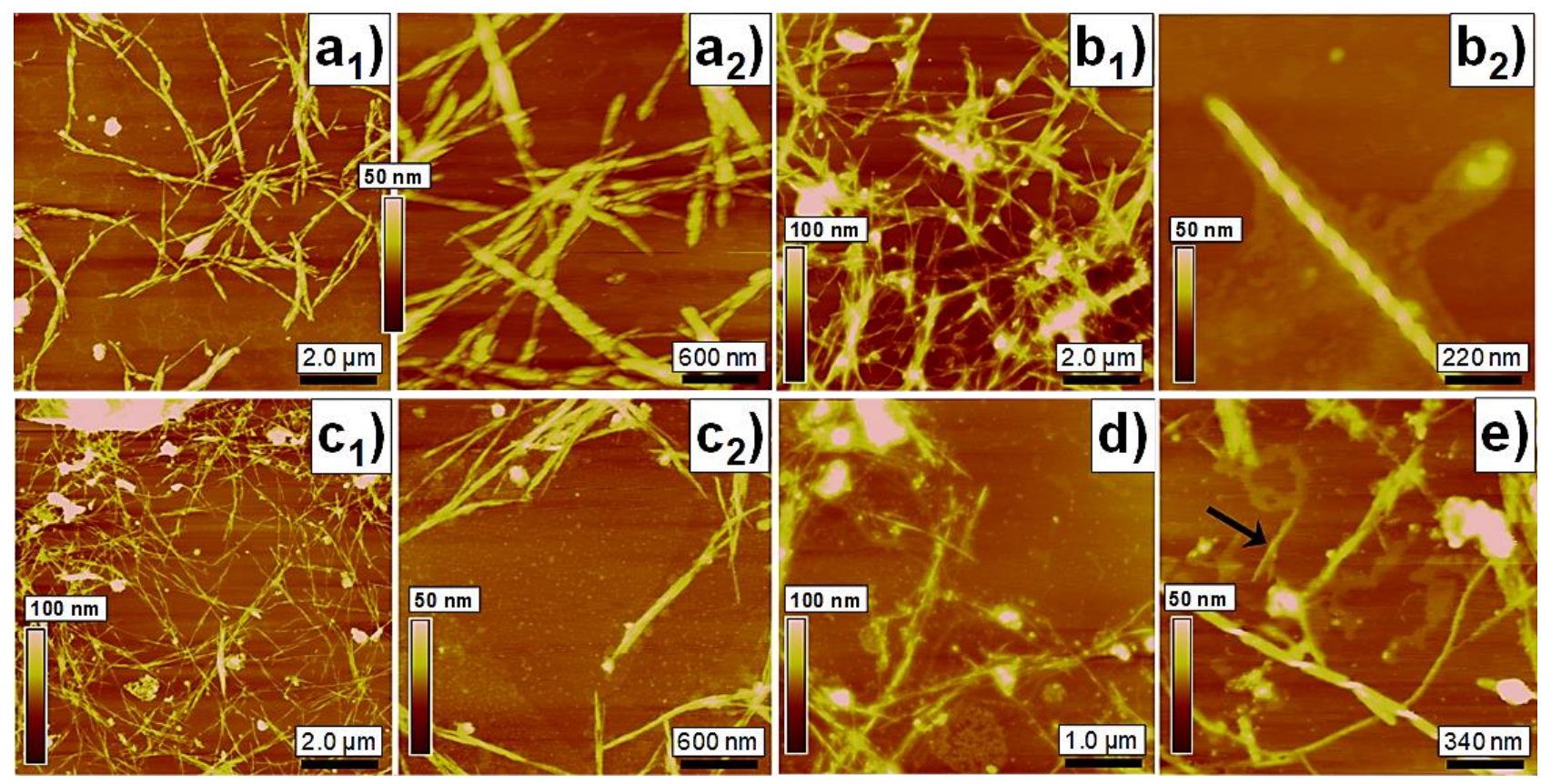

Figure 6. Atomic force microscopy height images of hydrolyzed BC after $74 \mathrm{~h}$ according to the following enzyme/BC ratios: (a) 1:4 at $10 \times 10 \mu \mathrm{m}^{2}$ (a $\mathrm{a}_{1}$ ) and $5 \times 5 \mu \mathrm{m}^{2}$ (a) ; (b) $1: 3$ at $10 \times 10 \mu \mathrm{m}^{2}$ (b) and $1 \times 1 \mu \mathrm{m}^{2}\left(\mathrm{~b}_{2}\right)$; (c) $1: 2$ at $10 \times 10 \mu \mathrm{m}^{2}\left(\mathrm{c}_{1}\right)$ and $3 \times 3 \mu \mathrm{m}^{2}\left(\mathrm{c}_{2}\right)$; (d) $1: 1$ at $5 \times 5 \mu \mathrm{m}^{2}$; and (e) $2: 1$ at $1.7 \times 1.7 \mu \mathrm{m}^{2}$. 
This confirmed the results of both the turbidity experiments and the yield experiments, as the 1:2 enzyme/BC ratio led to a unique hydrolysis kinetic pattern that was reflected in the hydrolyzed $\mathrm{BC}$ 's ultimate structural characteristics.

For the 1:1 and 2:1 mixtures, a progressive thinning was observed by increasing the enzyme concentration, with individual nanocrystals as thin as $\sim 6 \mathrm{~nm}$ (means: $12.1 \pm 4.9 \mathrm{~nm}$ and $8.6 \pm 1.3 \mathrm{~nm}$ for the 1:1 and 1:2 mixtures, respectively) and of 200-800 nm in length (mean: $345 \pm 7 \mathrm{~nm}$ for the 1:2 mixture; see Figures $5 \mathrm{~d}$ and $5 \mathrm{e}$ ). For the 2:1 mixture, a tendency toward reaggregation of the individual nanocrystals was detected (Figure 5e), which would explain the decreasing trend in the final part of the transmittance curve during the turbidity experiments (see Figure 1). In general, while the morphology of the hydrolyzed BC tended to thinner particles, the simultaneous presence of large particles was observed even for the enzyme-richest mixtures, confirming the larger polydispersity of BC-derived nanoparticles over the plant-derived counterpart. ${ }^{10,62}$ The progressive reduction in size was confirmed via a particle-size analysis (Figure 7). Although we are aware of the inadequacy of the DLS technique in determining the absolute size distribution of nonspherical particles, we decided to use this analysis in this work to gather relative information on the size reduction of hydrolyzed BC as a function of the enzyme/BC ratio. Therefore, though the absolute size values reported here should be considered with caution, a clear shift toward a lower size occurred as the enzyme/BC ratio decreased. Interestingly, the peaks pertaining to the 1:1 and 2:1 mixtures almost overlapped, providing further indication that the $\mathrm{BCNCs}$ reaggregated in the mixtures that were richest in enzymes. The thinning of the hydrolyzed BC particles when the enzyme concentration increases seems to suggest a peripheral attack of the enzyme, which would align with the model that MartínezSanz et al. proposed, according to which BC ribbons can be considered two-phase systems composed of a core of solvent-impermeable crystallites and an outer shell of paracrystalline and amorphous cellulose. ${ }^{60}$ 


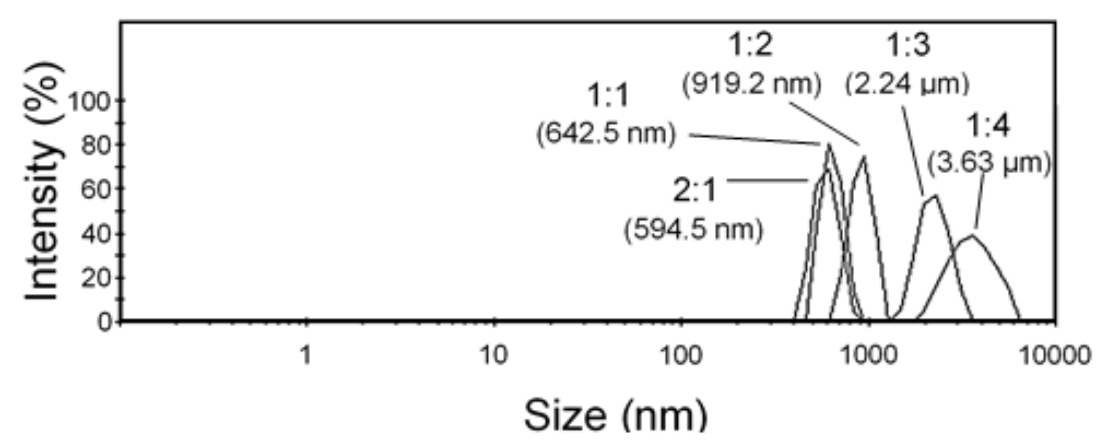

Figure 7. Size-distribution intensity plot of hydrolyzed BC after $74 \mathrm{~h}$, using dynamic light-scattering, for the 1:4, 1:3,1:2, 1:1, and 2:1 enzyme/BC ratios. The mean particle sizes are in parentheses.

Notably, long particles in the form of fibrils or flat ribbons were also observed in the enzymerich mixtures (Figures $6 \mathrm{~d}$ and $6 \mathrm{e}$ ), though to a lesser extent than in the 1:4, 1:3, and 1:2 mixtures. This clearly shows that the enzymatic hydrolysis is generates a certain degree of unevenness, that is, some very smooth and well-defined nanoparticles but also remaining bundles. The simultaneous presence of nanocrystals (see the arrow in Figure 6e) and bigger particles seems to corroborate the heterogeneous substrate model, which assumes a natural heterogeneity of cellulose structure in which hydrolysis only changes the proportions of structural elements with different structural properties. At the same time, the various $\mathrm{BCNC}$ morphologies and the high glucose concentrations, especially in the 1:1 and 2:1 mixtures, lead us to consider the surface-erosion model as a plausible way to describe the random action of cellulases on the surfaces of crystalline domains ${ }^{63}$ In addition, as was postulated for the 2:1 mixture after the turbidity experiments, the random erosion of the crystalline surface was the probable reason for the observed reaggregation of microfibril bundles $;{ }^{67}$ this was confirmed via microscopy analyses.

Finally, it is interesting to note that twisted ribbons with various sizes and periodicities were observed in all samples (see Figure $5 b_{2}$ and Figures $6 b_{2}$ and $6 e$ ). This feature of BC is known, ${ }^{68}$ though it is not clear whether the twists are biological in origin (caused by rotational movements of bacteria or enzyme complexes), physical (caused by the chiral nature of cellulose), or a combination 
of these. ${ }^{69}$ Similar morphologies have been extensively described for fibrillar proteins (e.g., amyloid fibrils), the structural features of which strongly depend on the mechanisms of fibrillation. ${ }^{70}$

\section{CONCLUSIONS}

Enzymatic hydrolysis of BC is a feasible route for obtaining nanocrystals. Pinpointing the optimal enzyme concentration, especially with respect to the amount of substrate that takes part in the reaction, is necessary for efficient downsizing of the parental macroscopic fibers. However, the simultaneous presence of particles with various morphologies (i.e., those with varied sizes and aspect ratios) confirmed the heterogeneous nature of the enzymatic hydrolysis. In addition, although the mixtures that were richest in enzymes provided the best outcome in terms of BCNCs, they were also characterized by very low yields, demonstrating the high intensity of EGs' and CBHs' hydrolytic action when performed in synergy, even for cellulose's crystalline regions. In this sense, the use of endoglucanases that selectively attack only the cellulose nanofibrils' amorphous domains could represent a step toward a more efficient process. At the same time, in line with the circular economy principles, the glucose that results from the hydrolytic process can be reused as fuel in the growth medium for the acid bacteria that produce $\mathrm{BC}$.

After this investigation, we would suggest setting the hydrolysis process at the $2: 1$ enzyme/BC ratio up to 30 hours of reaction or, alternatively, the 1:1 enzyme/BC ratio up to $\sim 45$ hours. After these temporal windows, it is possible to achieve a yield approaching $25 \%$ with a final morphology mostly represented by BCNCs. However, the zero net electrical charge on the surface of the BCNCs resulting from the enzymatic process has to be addressed in order to obtain stable suspensions over time. In this regard, using surfactants and/or polyelectrolytes to act as spacers, or inducing surface modifications on the cellulose backbone could be valid options.

The information gathered in this study is primarily meant to benefit the scientific community, particularly materials scientists who are looking for an alternative approach for obtaining cellulose nanocrystals that is greener than chemical hydrolysis routes. This study's ultimate impact is of general 
interest, as cellulose nanocrystals are increasingly being considered for applications in various fields, including medical/biomedical devices, purification/cleaning systems (e.g., membranes), displays, green building materials (e.g., insulating panels), and packaging solutions.

\title{
ASSOCIATED CONTENT
}

The Supporting Information is available free of charge on the ACS Publications website at DOI:

Detailed plots of the modeling of experimental transmittance data for the enzyme/BC mixtures $2: 1$, $1: 1,1: 2,1: 3$, and 1:4; main statistical parameters arising from the fitting procedure.

\author{
AUTHOR INFORMATION \\ Corresponding Author \\ Email address: stefano.farris@unimi.it \\ Tel.: +39 0250316805; Fax: +390250316672 \\ ORCID: 0000-0002-6423-8443
}

\section{Author Contributions}

The paper was written through contributions of all authors. All authors have given approval to the final version of the paper.

\section{Notes}

The authors declare no competing financial interest.

\section{ACKNOWLEDGEMENTS}

We are thankful to the Cariplo Foundation for its financial support (NANOSAK grant \# 2015-0464) and its promotion of scientific research. 


\section{REFERENCES}

1. Gama, M.; Gatenholm, P.; Klemm, D. Bacterial NanoCellulose A Sophisticated Multifunctional Material; CRC Press: Boca Raton, FL, 2012.

2. Yamada, Y.; Yukphan, P.; Lan Vu, H. T.; Muramatsu, Y.; Ochaikul, D.; Tanasupawat, S.; Nakagawa, Y. Description of Komagataeibacter gen. nov., with proposals of new combinations (Acetobacteraceae). J. Gen. Appl. Microbiol. 2012, 58 (5), 397-404, DOI 10.2323/jgam.58.397.

3. Dufresne, A. Nanocellulose: From Nature to High Performance Tailored Materials; Walter de Gruyter GmbH: Berlin, Germany, 2013.

4. Gilkes, R. N.; Jervis, E.; Henrissat, B.; Tekant, B.; Miller, C. R. Jr.; Warren, J. A. R.; Kilburn, G. D. The adsorption of a bacterial cellulase and its two isolated domains to crystalline cellulose. $J$. Biol. Chem. 1992, 267 (10), 6734-6749.

5. Czaja, W.; Romanovicz, D.; Malcolm Brown, R. Structural investigations of microbial cellulose produced in stationary and agitated culture. Cellulose 2004, 11 (3-4), 403-411, DOI 10.1023/b:cell.0000046412.11983.61.

6. Sacui, I. A.; Nieuwendaal, R. C.; Burnett, D. J.; Stranick, S. J.; Jorfi, M.; Weder, C.; Foster, E. J.; Olsson, R. T.; Gilman, J. W. Comparison of the Properties of Cellulose Nanocrystals and Cellulose Nanofibrils Isolated from Bacteria, Tunicate, and Wood Processed Using Acid, Enzymatic, Mechanical, and Oxidative Methods. ACS Appl. Mater. Interfaces 2014, 6 (9), 6127-6138, DOI 10.1021/am500359f.

7. Nishiyama, Y.; Langan, P.; Chanzy, H. Crystal structure and hydrogen-bonding system in cellulose I $\beta$ from synchrotron X-ray and neutron fiber diffraction. J. Am. Chem. Soc. 2002, 124 (31), 9074-9082, DOI 1021/ja0257319.

8. Guhados, G.; Wan, W.; Hutter, J. L. Measurement of the Elastic Modulus of Single Bacterial Cellulose Fibers Using Atomic Force Microscopy. Langmuir 2005, 21 (14), 6642-6646, DOI 10.1021/la0504311. 
9. Hsieh, Y.-C.; Yano, H.; Nogi, M.; Eichhorn, S. J. An estimation of the Young's modulus of bacterial cellulose filaments. Cellulose 2008, 15 (4), 507-513, DOI 10.1007/s10570-008-9206-8.

10. Reiling, S.; Brickmann, J. Theoretical investigations on the structure and physical-properties of cellulose. Macromol. Theor. Simul. 1995, 4 (4), 725-743, DOI 10.1002/mats.1995.040040409.

11. Eichhorn, S. J.; Davies, G. R. Modelling the crystalline deformation of native and regenerated cellulose. Cellulose 2006, 13 (3), 291-307, DOI 10.1007/s10570-006-9046-3.

12. Olsson, R. T.; et al. Cellulose nanofillers for food packaging. In Multifunctional and Nanoreinforced Polymers for Food Packaging; Lagaron, J.-M., Editor; Woodhead Publishing Limited: Oxford, U.K., 2011, DOI 10.1533/9780857092786.1.86.

13. Donini, I.; De Salvi, D; Fukumoto, F; Lustri, W; Barud, H; Marchetto, R.; Messaddeq, Y; Ribeiro, S. Biossíntese e recentes avanços naprodução de celulose bacteriana. Ecl. Quím. 2010 35, $165-178$.

14. Abdul Khalil, H. P. S.; Davoudpour, Y.; Nazrul Islam, M.; Mustapha, A.; Sudesh, K.; Dungani, R.; Jawaid, M. Production and modification of nanofibrillated cellulose using various mechanical processes: a review. Carbohydr. Polym. 2014, 99, 649-665, DOI 10.1016/j.carbpol.2013.08.069.

15. Agbor, V. B.; Cicek, N.; Sparling, R.; Berlin, A.; Levin, D. B. Biomass pretreatment: Fundamentals toward application. Biotechnol. Adv. 2011, 29, 675-685, DOI 10.1016/j.biotechadv.2011.05.005.

16. Dourado, F.; et al. Process modeling and techno-economic evaluation of an industrial bacterial nanocellulose fermentation process. In Bacterial NanoCellulose from Biotechnology to BioEconomy; Gama, M.; Dourado, F.; Bielecki, S., Editors; Elsevier: Amsterdam, Netherlands, 2016, DOI 10.1016/B978-0-444-63458-0.00012-3.

17. Gatenholm, P.; et al. effect of cultivation conditions on the structure and morphological properties of BNC biomaterials with a focus on vascular grafts. In Bacterial NanoCellulose $-A$ 
Sophisticated Multifunctional Material; Gama, M.; Gatenholm, P.; Klemm, D., Editors; CRC Press: Boca Raton, FL, 2013.

18. Keshk, S. M. Bacterial cellulose production and its industrial applications. Bioproces. Biotechniq. 2014, 4, 150, DOI 10.4172/2155-9821.1000150.

19. Leung, A. C. W.; Hrapovic, S.; Lam, E.; Liu, Y.; Male, K. B.; Mahmoud, K. A.; Luong, J. H. T. Characteristics and properties of carboxylated cellulose nanocrystals prepared from a novel onestep procedure. Small 2011, 7, 302-305, DOI 10.1002/smll.201001715.

20. Hamad, W. Y.; Hu, T. Q. Structure-process-yield interrelations in nanocrystalline cellulose extraction. Can. J. Eng. Chem. 2010, 88, 392-402, DOI 10.1002/cjce.20298.

21. Huang, Y.; Zhu, C.; Yang, J.; Nie, Y.; Chen, C.; Sun, D. Recent advances in bacterial cellulose. Cellulose 2014, 21 (1), 1-30, DOI 10.1007/s10570-013-0088-z.

22. Phisalaphong, M.; et al. Applications and Products-Nata de Coco. In Bacterial NanoCellulose: A Sophisticated Multifunctional Material; Gama, M., Gatenholm, P., Klemm, D., Eds.; CRC Press: Boca Raton, FL., 2012.

23. Jozala, A. F.; de Lencastre-Novaes, L. C.; Lopes, A. M.; de Carvalho Santos-Ebinuma, V.; Mazzola, P. G.; Pessoa, A. Jr.; Grotto, D.; Gerenutti, M.; Chaud, M. V. Bacterial nanocellulose production and application: a 10-year overview. Appl. Microbiol. Biotechnol. 2016, 100 (5), 20632072, DOI 10.1007/s00253-015-7243-4.

24. Campano, C.; Balea, A.; Blanco, A.; Negro,C. Enhancement of the fermentation process and properties of bacterial cellulose: a review. Cellulose 2016, 23 (1), 57-91, DOI 10.1007/s10570-0150802-0.

25. Habibi, Y.; Lucia, L. A.; Rojas, O. J. Cellulose nanocrystals: chemistry, self-assembly, and applications. Chem. Rev. 2010, 110 (6), 3479-3500, DOI 10.1021/cr900339w.

26. Yoo, Y. Youngblood, J. P. Green one-pot synthesis of surface hydrophobized cellulose nanocrystals in aqueous medium. ACS Sustainable Chem. Eng. 2016, 4 (7), 3927-3938, DOI 10.1021/acssuschemeng.6b00781. 
27. Huang, L. Ye, Z., Berry, R. Modification of cellulose nanocrystals with quaternary ammonium-containing hyperbranched polyethylene ionomers by ionic assembly. ACS Sustainable Chem. Eng. 2016, 4 (9), 4937-4950, DOI 10.1021/acssuschemeng.6b01253.

28. Cheng, M., Qin, Z., Chen, Y., Hu, S., Ren, Z., Zhu, M. Efficient extraction of cellulose nanocrystals through hydrochloric acid hydrolysis catalyzed by inorganic chlorides under hydrothermal conditions. ACS Sustainable Chem. Eng. 2017, 5 (6), 4656-4664, DOI 10.1021/acssuschemeng.6b03194.

29. Xie, D.-Y., Qian, D. Song, F., Wang, X.-L., Wang, Y.-Z. A Fully Biobased encapsulant constructed of soy protein and cellulose nanocrystals for flexible electromechanical sensing. ACS Sustainable Chem. Eng. 2017, 5 (8), 7063-7070, DOI 10.1021/acssuschemeng.7b01266.

30. Nan, F. Nagarajan, S., Chen, Y., Liu, P., Duan, Y., Men, Y., Zhang, J. Enhanced toughness and thermal stability of cellulose nanocrystal iridescent films by alkali treatment. ACS Sustainable Chem. Eng. 2017, 5 (10), 8951-8958, DOI 10.1021/acssuschemeng.7b01749.

31. Kedzior, S. A., Dubé, M. A., Cranston, E. D. Cellulose nanocrystals and methyl cellulose as costabilizers for nanocomposite latexes with double morphology. ACS Sustainable Chem. Eng. 2017, 5 (11), 10509-10517, DOI 10.1021/acssuschemeng.7b02510.

32. George, J.; Ramana, K. V.; Bawa, A. S.; Siddaramaiah. Bacterial cellulose nanocrystals exhibiting high thermal stability and their polymer nanocomposites. Int. J. Biol. Macromol. 2011, 48 (1), 50-57, DOI 10.1016/j.ijbiomac.2010.09.013.

33. Liu, Y., Guo, B., Xia, Q., Meng, J., Chen, W., Liu, S., Wang, Q., Liu, Y., Li, J., Yu, H. Efficient cleavage of strong hydrogen bonds in cotton by deep eutectic solvents and facile fabrication of cellulose nanocrystals in high yields. ACS Sustainable Chem. Eng., 2017, 5 (9), 7623-7631, DOI 10.1021/acssuschemeng.7b00954.

34. Mishra, S. P.; Manent, A.-S.; Chabot, B.; Daneault, C. Production of nanocellulose from native cellulose - Various options utilizing ultrasound. Bioresources 2012, 7 (1), 422-436, DOI 10.15376/biores.7.1.0422-0436. 
35. Tang, L.; Huang, B.; Lu, Q.; Wang, S.; Ou, W.; Lin, W.; Chen, X. Ultrasonication-assisted manufacture of cellulose nanocrystals esterified with acetic acid. Bioresour. Technol. 2013, 127, 100105, DOI 10.1016/j.biortech.2012.09.133.

36. Yang, B.; Dai, Z.; Ding, S.-Y.; Wyman, C. E. Enzymatic hydrolysis of cellulosic biomass. Biofuels 2011, 2 (4), 421-450, DOI 10.4155/bfs.11.116.

37. Li, Y.; Liu, Y.; Chen, W.; Wang, Q.; Liu, Y.; Li, J.; Yu, H. Facile extraction of cellulose nanocrystals from wood using ethanol and peroxide solvothermal pretreatment followed by ultrasonic nanofibrillation. Green Chem. 2016, 18 (4), 1010-1018, DOI 10.1039/C5GC02576A.

38. Rabinovich, M. L.; Melnick, M. S.; Bolobova, A. V. The structure and mechanism of action of cellulolytic enzymes. Biochem. (Moscow) 2002, 67 (8), 850-871, DOI 10.1023/a:1019958419032. 39. Ahola, S.; Turon, X.; Osterberg, M.; Laine, J.; Rojas, O. J. Enzymatic Hydrolysis of Native Cellulose Nanofibrils and Other Cellulose Model Films: Effect of Surface Structure. Langmuir 2008, 24 (20), 11592-11599, DOI 10.1021/la801550j.

40. Väljamäe, P.; Sild, V.; Nutt, A.; Pettersson, G.; Johansson, G. Acid hydrolysis of bacterial cellulose reveals different modes of synergistic action between cellobiohydrolase I and endoglucanase I. Eur. J. Biochem. 1999, 266 (2), 327-334, DOI 10.1046/j.1432-1327.1999.00853.x. 41. Santa-Maria, M.; Jeoh, T. Molecular-scale investigations of cellulose microstructure during enzymatic hydrolysis. Biomacromolecules 2010, 11, 2000-2007, DOI 10.1021/bm100366h.

42. Hu, Y.; Catchmark, J. M. Integration of cellulases into bacterial cellulose: Toward bioabsorbable cellulose composites. J. Biomed. Mater. Res. Part B Appl. Biomater. 2011, 97B, 114123, DOI 10.1002/jbm.b.31792.

43. Wang, B.; Lv, X.; Chen, S.; Li, Z.; Sun, X.; Feng, C.; Wang, H-; Xu, Y. In vitro biodegradability of bacterial cellulose by cellulose in simulated body fluid and compatibility in vivo. Cellulose 2016, 23, 3187-3198, DOI 10.1007/s10570-016-0993-z. 
44. Domingues, A. A.; Pereira, F. V.; Sierakowski, M. R.; Rojas, O. J.; Petri, D. F. S. Interfacial properties of cellulose nanoparticles obtained from acid and enzymatic hydrolysis of cellulose. Cellulose 2016, 23, 2421-2437, DOI 10.1007/s10570-016-0965-3.

45. Bansal, P.; Hall, M.; Realff, M. J.; Lee, J. H.; Bommarius. A. S. Modeling cellulase kinetics on lignocellulosic substrates. Biotechnol. Adv. 2009, 27 (6), 833-848, DOI 10.1016/j.biotechadv.2009.06.005.

46. Väljamäe, P.; Kipper, K.; Pettersson, G.; Johansson, G. Synergistic cellulose hydrolysis can be described in terms of fractal-like kinetics. Biotechnol. Bioeng. 2003, 84 (2), 254-257, DOI 10.1002.bit.10775.

47. Frade, R. F. M.; Matias, A.; Branco, L. C.; Alfonso, C. A. M.; Duarte, C. M. M. Effect of ionic liquids on human colon carcinoma HT-29 and CaCo-2 cell lines. Green Chem. 2007, 9 (8), 873877, DOI 10.1039/b617526k.

48. Shen, L. Q.; Melnikov, F.; Roethle, J.; Gudibanda, A.; Judson, R. S.; Zimmermana, J. B.; Anastas, P. T. Coupled molecular design diagrams to guide safer chemical design with reduced likelihood of perturbing the NRF2-ARE antioxidant pathway and inducing cytotoxicity. Green Chem. 2016, 18 (23), 6387-6394, DOI 10.1039/C6GC02073A.

49. Sintra, T. E., Luís, A., Rocha, S. N., Lobo Ferreira, A. I. M. C., Gonçalves, F., Santos, L. M. N. B. F., Neves, B. M., Freire, M. G., Ventura, S. P. M., Coutinho, J. A. P. Enhancing the antioxidant characteristics of phenolic acids by their conversion into cholinium salts. ACS Sustainable Chem. Eng. 2015, 3 (10), 2558-2565, DOI 10.1021/acssuschemeng.5b00751.

50. Grimm, F. A.; Iwata, Y.; Sirenko, O.; Chappell, G. A.; Wright, F. A.; Reif, D. M.; Braisted, J.; Gerhold, D. L.; Yeakley, J. M.; Shepard, P.; Seligmann, B.; Roy, T.; Boogaard, P. J.; Ketelslegers, H. B.; Rohdei, A. M.; Rusyn, I. A chemical-biological similarity-based grouping of complex substances as a prototype approach for evaluating chemical alternatives. Green Chem. 2016, 18 (16), 4407-4419, DOI 10.1039/C6GC01147K. 
51. Neumann, J.; Cho, C.-W.; Steudte, S.; Koser, J.; Uerdingen, M.; Thoming, J.; Stolte, S. Biodegradability of fluoroorganic and cyano-based ionic liquid anions under aerobic and anaerobic conditions. Green Chem. 2012, 14, 410-418, DOI 10.1039/C1GC16170A.

52. Domaille, D. W., Hafenstine, G. R., Greer, M. A., Goodwin, A. P., Cha, J. N. Catalytic upgrading in bacteria-compatible conditions via a biocompatible aldol condensation. ACS Sustainable Chem. Eng. 2016, 4 (3), 671-675, DOI 10.1021/acssuschemeng.5b01590.

53. Akkermans, S.; Van Impe, J. F. Mechanistic modelling of the inhibitory effect of pH on microbial growth. Food Microbiol. 2018, 72, 214-219, DOI 10.1016/j.fm.2017.12.007.

54. Morandeira, L., Alvarez, M. S., Markiewicz, M., Stolte, S., Rodríguez, A., Sanromán, M. A., Deive, F. J. Testing true choline ionic liquid biocompatibility from a biotechnological standpoint. ACS Sustainable Chem. Eng. 2017, 5 (9), 8302-8309, DOI 10.1021/acssuschemeng.7b02017.

55. Nakamoto, H.; Nishikubo, D.; Kobayashi. F. Food texture evaluation using logistic regression model and magnetic food texture sensor. J. Food Eng. 2018, 222, 20-28, DOI 10.1016/j.jfoodeng.2017.11.008.

56. Ståhlberg, J.; Johannson, G.; Pettersson, G. A new model for enzymatic hydrolysis of cellulose based on the two-domain structure of cellobiohydrolase I. Nat. Biotechnol. 1991, 9, 28690, DOI 10.1038/nbt0391-286.

57. Jervis, E. J.; Haynes, C. A.; Kilburn, D. G. Surface diffusion of cellulases and their isolated binding domains on cellulose. J. Biol. Chem. 1997, 272 (38), 24016-24023, DOI 10.1074/jbc.272.38.24016.

58. Mulakala, C.; Reilly, P. J. Hypocrea jecorina (Trichoderma reesei) Cel7A as a molecular machine: a docking study. Proteins Struct. Funct. Bioinf. 2005, 60 (4), 598-605, DOI 10.1002/prot.20547.

59. Wood, M. T.; et al. Synergism between enzymes involved in the solubilization of native cellulose. In Hydrolysis of Cellulose: Mechanisms of Enzymatic and Acid Catalysis; Brown, R. D., 
Jurasek, L., Eds.; AMERICAN CHEMICAL SOCIETY: Washington, D.C., United States, 1979, DOI 10.1021/ba-1979-0181.ch010.

60. Martınez-Sanz, M.; Gidley, M. J.; Gilbert, E. P. Hierarchical architecture of bacterial cellulose and composite plant cell wall polysaccharide hydrogels using small angle neutron scattering. Soft Matter 2016, 12 (5), 1534-1549, DOI 10.1039/C5SM02085A.

61. Klemm, D.; Kramer, F.; Moritz, S.; Lindstrom, T.; Ankerfors, M.; Gray, D.; Dorris, A. Nanocelluloses: A New Family of Nature-Based Materials. Angew. Chem. Int. Ed. 2011, 50 (24), 5438-5466, DOI 10.1002/anie.201001273.

62. Moon, R. J.; Martini, A.; Nairn, J.; Simonsen, J.; Youngblood, J. Cellulose nanomaterials review: structure, properties and nanocomposites. Chem. Soc. Rev. 2011, 40 (7), 3941-3994, DOI 10.1039/C0CS00108B.

63. Väljamäe, P.; Sild, V.; Pettersson, G.; Johansson, G. The initial kinetics of hydrolysis by cellobiohydrolases I and II is consistent with a cellulose surface - erosion model. Eur. J. Biochem. 1998, 253 (2), 469-475, DOI 10.1039/C0CS00108B.

64. Martinez-Sanz, M.; Lopez-Sanchez, P.; Gidley, M. J.; Gilbert, E. P. Evidence for differential interaction mechanism of plant cell wall matrix polysaccharides in hierarchically-structured bacterial cellulose. Cellulose 2015, 22 (3), 1541-1563, DOI 10.1007/s10570-015-0614-2.

65. Tokoh, C.; Takabe, K.; Sugiyama, J.; Fujita, M. Cellulose synthesized by Acetobacter xylinum in the presence of plant cell wall polysaccharides. Cellulose 2002, 9 (1), 65-74, DOI 10.1023/a:1015827121927.

66. Kumagai, A.; Mizuno, M.; Kato, N.; Nozaki, K.; Togawa, E.; Yamanaka, S.; Okuda, K.; Saxena, I. M.; Amano, Y. Ultrafine cellulose fibers produced by Asaia bogorensis, an acetic acid bacterium. Biomacromolecules 2011, 12 (7), 2815-2821, DOI 10.1021/bm2005615.

67. Samejima, M.; Sugiyama, J.; Igarashi, K.; Eriksson. L. K.-E. Enzymatic hydrolysis of bacterial cellulose. Carbohydr. Res. 1997, 305 (2), 281-288, DOI 10.1016/S0008-6215(97)10034-9. 
68. Van Daele, Y.; Revol, J.-F.; Gaill, F.; Goffinet, G. Characterization and supramolecular architecture of the cellulose-protein fibrils in the tunic of the sea peach (Halocynthia papillosa, Ascidiacea, Urochordata). Biol. Cell 1992, 76 (1), 87-96, DOI 10.1016/0248-4900(92)90198-A.

69. Elazzouzi-Hafraoui, S.; Nishiyama, Y.; Putaux, J.-L.; Heux, L.; Dubreuil, F.; Rochas, C. The Shape and Size Distribution of Crystalline Nanoparticles Prepared by Acid Hydrolysis of Native Cellulose. Biomacromolecules 2008, 9 (1), 57-65, DOI 10.1021/bm700769p.

70. Adamcik, J.; Mezzenga, R. Study of amyloid fibrils via atomic force microscopy. Curr. Opin. Colloid Interface Sci. 2012, 17 (6), 369-376, DOI 10.1016/j.cocis.2012.08.001. 


\section{For Table of Contents Use Only}

\section{Graphical Abstract}

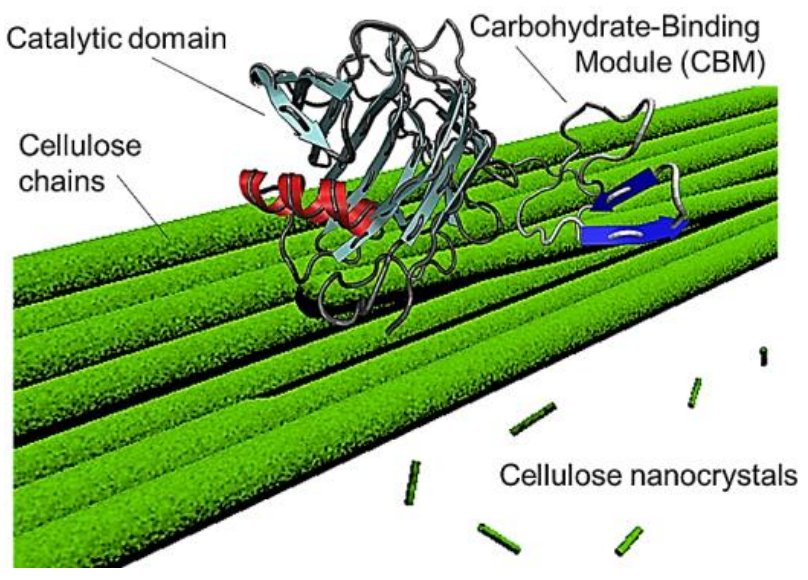

\section{Synopsis}

Cellulose nanocrystals can be extracted from bacterial cellulose by enzymatic hydrolysis, which represents an alternative green method to the most widely adopted chemical (e.g., acid) hydrolysis. 